\title{
Italy widens peer review of health research
}

Rome. Italy's largest health research institute, the Istituto Superiore di Sanità (the Higher Institute of Health) has won the right to distribute funds for some of its research programmes, previously restricted to staff scientists, to research groups elsewhere in Italy.

Leading researchers at the institute will take responsibility for running these programmes and in particular for establishing peer review systems that will ensure grant applications are approved solely on the basis of scientific merit, rather than to meet an administrative or political agenda.

The institute was founded in 1934 by the Rockefeller Foundation, and now controls a total annual budget of IL300 billion (US\$ 173million). It has a staff of 1,400 , a third of whom are scientists, and carries out regulatory and advisory activities for the government, including setting standards and monitoring the quality of blood products.

In addition, the institute receives funds to support research related to public health, following a programme agreed between the Ministry of Health and the institute's scientific committee. (Basic biomedical research in Italy is supported by the Consiglio Nazionale della Ricerche, the CNR).

Until recently, research programmes were conducted exclusively within the institute. But in 1987 a new law was passed allowing a committee at the institute, headed by Giovanni Rossi, a virologist, to run the Italian AIDS research programme. This receives around IL28 billion a year, nearly half of which is destined for basic research into the pathogenesis of HIV infection. The programme became widely admired for its efficient administration and in particular for introducing a formal system of evaluating grant applications, based on peer review by both Italian and foreign scientists.

Italy's lax standards in evaluating grants supported by public research funds, and the lack of transparency of many grant-giving bodies such as the CNR, which does not publicly state its criteria for awarding grant money, have long been a source of frustration, particularly among leading scientists (see Nature 367, 398; 1994).

"Universities, for example, have adopted the rain principle," says Fernando Aiuti, professor of immunology at the University of Rome 'La Sapienza', and a leading AIDS researcher. "Everyone gets a drop and they are therefore kept happy." But, he points out, no-one gets enough money from a single grant application to do significant work.

In contrast, he says, those responsible for the AIDS research programme have not been afraid to provide large sums to only a few of the best research groups, he says. Each application is reviewed by six experts inside Italy and two from abroad. "This type of system, with referees, is the only one that guarantees honesty and high standards," comments Aiuti.

The director of the Istituto Superiore di Sanità, Giuseppe Vicari, has been keen to extend this approach to other research programmes financed by the health ministry. It

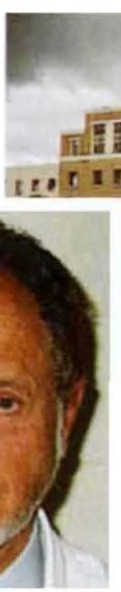

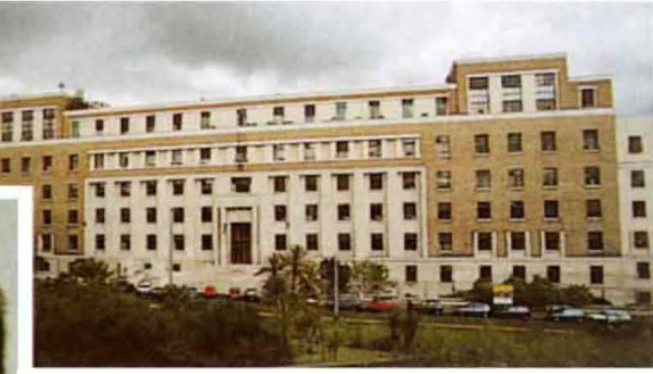

Aiuti (left): says peer review "guarantees high standards"; (above) Istituto Superiore di Sanità
In 1973 a new law, intended to introduce more democracy into the administrative structures, was passed setting up an advisory scientific council and an executive administrative council, both with elected representatives from all staff levels.

But the new arrangements proved unwieldy and in 1992, as part of government efforts to make Italy's public sector more efficient, a further law was passed, allowing changes in the national health service. As a result, a decree took effect last month reforming the tasks and structure of the institute's two councils.

The scientific council, which is required to express its views on all scientific activities at the institute, will now have only three elected members, representing research staff. All the institute's laboratory directors (around 15) will automatically be members. Nominated repretook some time to convince the Court of Accounts that the 1987 law could be applied to other research areas, as the law referred only to AIDS research. But after a meeting between the court and Vicari earlier this month, the principle was accepted. "This means nine other areas, including tuberculosis, multiple sclerosis, hepatitis and gene therapy, may now be handled similarly," says Vicari.

The Istituto Superiore di Sanità has other reasons to feel optimistic about its future as a research institute because, after many years of political uncertainty, it is finally getting itself on a firmer footing.

The institute lost much of its original prestige during the 1960 s, when many areas of Italian life became politically polarized. The founding director, Domenico Marotta, and his left-of-centre scientific and administrative boards, fell out of favour with the ruling Christian Democrats. Under pressure to retire, Marotta was eventually charged with misusing funds and jailed, while many scientists left the institute.

\section{UK virology institute 'to change direction'}

London. David Bishop, director of the Natural Environment Research Council's Institute of Virology and Environmental Microbiology outside Oxford, has been removed from his post. He was told last week that the research council is seeking a new director for the institute.

The institute has been at the centre of a fierce public controversy about experiments involving field trials of a potential pesticide based on a plant virus genetically engineered to express a scorpion toxin.

But NERC officials deny any link with sentatives from relevant ministries and regional governments complete the council.

One task of the new council will be to monitor potential conflict of interests over research funded from outside sources. For the first time, researchers at the institute will be able to accept private funding, including that from the pharmaceutical industry. But some staff members fear this could conflict with the main concern of the institute, namely the improvement of public health.

The issue is particularly sensitive because the previous director, Francesco-Antonio Manzola, formerly professor of anatomy at the University of Bologna, was arrested in 1993 on corruption charges relating to the fixing of drug prices. Although the institute was not associated with the scandal, its scientists are acutely conscious of the embarrassment they were caused.

The administrative council, which previously had to approve every minor expenditure, will now have less day-to-day control, and will be required only to approve a general budget annually, and to check expenditure at the end of the year. Alison Abbott

the controversy, which first erupted when local residents claimed they had not been properly informed about the experiments. In a prepared statement, the council said that the move followed a review carried out in line with government policy.

"It has been decided the mission of the institute will be refocussed to undertake basic and strategic research to generate an understanding of the biodiversity and functional roles of microbial populations in the environment," said the statement from the council. 